\title{
En fidelidad al evangelio \\ y al pueblo salvadoreño. El diario pastoral de Mons. Romero. Parte final.
}

\author{
Rodolifo Cardenal, \\ Centro de Reflexión Teológlca, \\ San Salvador.
}

Las siguientes páginas saldan una vieja deuda con los lectores de la revisla. En el número 4, correspondiente a enero-abril de 1985, con el título "En fidelidad al avangelio y al pueblo salvadoreño. El diario pastoral de Mons. Romero" publiqué las dos primeras parles de un arlculo de tres sobre el diario grabado de Mons. Romero. En aquella ocasión no hubo oportunidad de publicar el estudio completo. La tercera parte sobre el conflicto eclesial durante su episcopado quedó esperando una mejor oportunidad. La redacción de la revista ha considerado ahora que esa oportunidad ha llegado. De este modo cumplimos la promesa de dar a conocer el lexto complelo.

En esta tercera parte, al igual que en las dos primeras, el análisis del diario sólo cubre el último año y medio de su arzobispado. Los conllictos eclesiales empezaron desde el momento en que asumí́ el arzobispado de San Salvador. El funeral de Rutilio Grande provocó un entrentamiento con el nuncio y con los demás obispos. El confliclo fue originado por una misa única que Mons. Romero presidió en la arquidiócesis. También hubo fuertes discusiones sobre el apostolado de Rulilio Grande. A este siguieron otros conflictos eclesiales, pero como no se hallan en el diario, tal como llegó a mis manos, han quedado fuera de estas páginas. Aquí, como en las dos partes anteriores, esta última parte se ciñe sólo al texto conservado en las grabaciones de Mons. Romero.

\section{Soledad, controversla y martirlo de un arzoblspo}

Monseñor, un arzobispo querido por sus obras, fue también un arzobispo conflictivo y atacado. En su Diario, Monseñor se muestra muy consciente de la doble imagen que réllejaba. Para unos él era el causante de todos los males de El Salvador, "como un monstruo de maldad;" para otro, "gracias a Dios," en especial para el pueblo sencillo, "soy el pastor." Así, en electo, se comprendió él a sl mismo como el pastor de todos los salvadreños, quien iba concretando el mismo mensaje a las diversas personas y grupos (11 de abril de 1978).

En esta tercera y última parle de este esludio presentamos las rellexiones que hizo Monseñor sobre la conflictividad que le ocasionó su fidelidad al evange- 
lio y al pueblo salvadoreño. Es impresionante la soledad que sentla dentro de la conlerencia episcopal (CEDES), en la cual solamente Monseñor Rivera lo apoyaba; las imcomprensiones y los alaques de parte de otros obispos, sus hermanos en el episcopado. Por otra parte, es impresionante la fidelidad eclesial de Monseñor Romero, la humildad con que él mismo analizaba su posible responsabilidad en la desunión episcopal, su esperanza y su oración por conseguirla. En este contexo, sus tres viajes a Roma lo muestran como el pastor que busca orientación y confirmación en el pastor supremo de la lglesia.

No podla terminar este estudio sin decir una palabra sobre el maririo de Monseñor. En medio de tan gran persecución a la lglesia y de represión al pueblo, Monseñor luvo que reflexionar por necesidad sobre la posibilidad de su propia muerte. Lo que resalta en esas reflexiones es su inquebrantable lidelidad al evangelio y a su pueblo y su solidaridad última con él: no quiso recibir ninguna seguridad mientras no se diera seguridad a su pueblo.

\section{Los conflletos con sus hermanos oblspos}

De acuerdo con el testimonio biográlico del Diario, el obispo con quien luvo mayores conflictos, en público y privado, fue Monseñor Aparicio, obispo de San Vicente en ese entonces. De estas acusaciones se aprovechaban luego otros tres obispos para manifestar su propio descontento con Monseñor y la arquidiócesis. En una frase de Monseñor se trataba de "un conjunto de acusaciones que ponen completamente en entredicho mi minislerio episcopal" (18 de mayo de 1979).

Monseñor Aparicio denunció la actuación del arzobispo de San Salvador y a la arquidiócesis en general. Asl, interpretaba la muerte de los sacerdotes como purgas de la izquierda, "que no se les permite retroceder" (17 de septiembre de 1979); prohibió leer a sus diocesanos el semanario de la arquidiócesis (17 de septiembre de 1979); acusó a los jesuitas de ser los responsables de la violencia y de defender lo indefendible al tratar de apoyar a Monseñor (3 de febrero de 1979); denunció la supuesta intiltración maxista en la lglesia y en concreto en la arquidiócesis, al menos asl interpretó Monseñor su actuación cuando la Policla Nacional liberó a un sacerdote de la dibcesis de San Vicente -la Policla Nacional hizo ver al obispo de San Vicente el respelo que habla lenido al sacerdote, no asl con un trabajador de la YSAX capturado junto con é- y cómo sólo estaban persiguiendo la infiltración maxxista, "lastimosamente, Monseñor Aparicio en vez de defender la causa de la Iglesia dio razón a los motivos de la policla, lo cual parece peligroso en cuanto al arzobispado. Pues se pretende dar la imagen de que el arzobispado exagera, de que francamente hay infiltración comunisla y de que no somos justos cuando denunciamos tanto atropello al pueblo y a la lglesia" (6 de octubre de 1978).

A Monseñor una de las cosas que más le preocupaba de las repetidas y falsas acusaciones del obispo de San Vicente era que exponla a la represión a los sacerdotes y a la manipulación de la derecha y del gobierno (27 de septiembre de 1979). Por eso, decidió de acuerdo con el senado, enviar una comisión a dialogar con el obispo para hacerle ver lo grave de su acusación, el apoyo que eso prestaba a los asesinos de los sacerdotes, a pedirle pruebas "porque necesitamos conocerlas, si existen, en verdad," y a pedirle un esfuerzo de unidad episcopal "para 
delender y no para acusar los derechos de nuestros sacerdotes y de nuestro pueblo" (17 de septiembre de 1979).

En las reuniones de la CEDES, Monseñor siempre fue "objeto de muchas acusaciones falsas" de parle de varios obispos. Monseñor Aparicio lo acusaba "de predicar la subversión y la violencia, de que sus sacerdotes eran predicadores de la violencia a los campesinos y que, por lo tanto, no debería quejarse de la reacción del gobierno, de interferir en las otras diócesis introduciendo en ellas la división en el clero y el malestar pastoral, de causar confusión en el seminario" y de ahl la urgencia de que sacara cuanto antes sus oficinas del edificio "y otra serie de acusaciones calumniosas y falsas..." (3 de abril de 1978).

El obispo de San Miguel, Monseñor Alvarez, "aprovechó (estas acusa. ciones de Monseñor Aparicio) para desahogar su inconformidad conmigo." apuntó Monseñor el 5 de abril de 1978. Otro tanto hizo el obispo de Santa Ana, pero "lo más extraño, Monseñor Revelo nombrado recientemente auxiliar (de San Salvador), también aprovechó para decir su incontormidad con mi Ilnea diciéndome que yo no era intalible cuando explicaba, ya que mi linea era precisamente la que trazan los documentos del Concilio, los documentos de las enclclicas de los papas y de Medellín. Según Monseñor Revelo yo puedo equivocarme en la aplicación de esos documentos y que por tanto no habla obligación de estar de acuerdo con esta línea" (5 de abril de 1978).

Litúrgicamente estos obispos marginaron a Monseñor. El 10 de marzo de 1979 aceptó la invitación de la CEDES, junlo con Monseñor Rivera, para depositar los documentos de Puebla ante Nuestra Señora de la Paz, en San Miguel. El interpretó su asistencia como un gesto de unidad episcopal, pero observó cómo "la ceremonia habla sido organizada por los directivos de la conferencia episcopal. Se noló claramente la exclusión de mi persona en la participación de la ceremonia. El pueblo (sin embargo) me tributó una aclamación inesperada a la salida, lo cual les he agradecido profundamente- (10 de marzo de 1979). Lo mismo sucedió el 21 de noviembre.

Ante estas acusaciones "falsas y calumniosas," Monsefior prefirió callarse. Su actitud en la reunión de la CEDES del 3 de abril de 1978 fue la de no contestar y comento en el Diario, "ha sido un dla amargado por esta circunstancia y lamentando que la división en el episcopado se aumente..." Ante estas acusaciones hechas el 5 de abril, "preferl callar el resto de la reunión ya que el documento que se publico solamente se leyo una vez y no se pidió ninguna aclaración, sino que se firmó bajo este apasionamiento, lo cual me contirmo en mis palabras que dije al principio, 'ya todo lo tienen cocinado"' (5 de abril de 1978). Al documento al que aquí se refiere es un texto hecho público por los otros cuatro obispos condenando una carta pública del clero contra el nuncio. Esta misma actitud de guardar silencio mostró, por recomendación de la curia, cuando un sacerdote lo crilicó en la prensa, "estuvimos de acuerdo en no darle importancia y lamentamos que esté entregado al gobierno," comentó en el Diario Monseñor (27 de mayo de 1978).

Orra actilud de Monseñor frente a estas acusaciones fue la de reconocer sus deficiencias personales y la de tratar de aprovechar lo que de verdadero habla en las afirmaciones de sus acusadores para corregirse. Ante un documento hecho circular por los otros obispos en su contra coment6 en el Diario, "las de- 
nuncias que se hacen en dicho documento encuenlran algo de verdad, que es necesario corregir, pero también hay mucho de exageración y casi calumnioso a lo cual no vamos a responder, sino con los hechos de continuar trabajando la pastoral de nuestra arquidiócesis" (21 de mayo de 1979). Lo mismo le dijo al senado al conocer un documento (en el Diario no especilica si es el mismo o se trata de otro distinto) leldo por el obispo de San Miguel a su clero en el cual denunciaba al arzobispo y a la arquidiócesis, "por mi parte les dije que aprovecharlamos esas crllicas para revisar con sinceridad y humildad nuestra actuación" (29 de mayo de 1979).

A pesar de lo grave y constante de estas acusaciones y calumnias lanzadas en su contra y en contra de la arquidiócesis, Monseñor mantuvo la paz interior, "he sentido mucha paz. Reconozco ante Dios mis deliciencias, pero creo que he trabajado con buena volunlad y lejos de las cosas graves que se me acusa. Dios dirá la última palabra y espero tranquilo seguir trabajando con el mismo entusiasmo de siempre, ya que sirvo con amor a la santa lglesia" (18 de mayo de 1979). Asl, pues, ante estos alaques, Monseñor experimentó un profundo dolor, por una parte, y una gran humidad, por la otra. En cualquier caso, siempre conservó la paz.

\section{La división en la CEDES}

El vaticano mostró preocupación por la división pública del episcopado salvadoreño. En el Diario, Monseñor dijo el 2 de julio de 1979 que el nuncio, recién llegado de Roma, le habla transmitido esa preocupación vaticana "y que esperaban mucho de mi colaboración para esta unidad. Yo expresé las razones que muchas veces he expuesto, de que hay algo personal en algunos de ellos y que para mi se me hace muy dificil esta tarea; sin embargo, haré lodo lo que esté a mi alcancen (2 de julio de 1979). En el Diario no se hace constar que lo mismo se hubiera pedido a los demás obispos de parte de las autoridades vaticanas.

El 11 de agosto de 1979, según el Diario, el nuncio reunió a la CEDES en la nunciatura para reflexionar sobre el asesinalo del Padre Alirio Napoleón Maclas, párroco de San Esteban Catarina, en la díbcesis de San Vicenle, hecho ocurido el 5 de agosto. En la reunión "únicamente se acordó denunciar oficialmente el asesinato" (11 de agosto de 1979). La discusión, según la versión de Monseñor, "conlirmó la división que existe entre nosotros... pero cuando se traló de ver las causas, se dejó llevar la junta por los prejuicios de una infiltración marxista dentro de la lglesia y no fue posible sacar de alli todos los prejuicios, a pesar de que traté de explicar que la situación de persecución de muchos sacerdotes, es por querar ser fieles al esplritu del Vaticano II. traducido a América Latina por Medellin y por Puebla. Muy poco se comprende esto y más bien se echa la culpa a una instrumentalización del maxismo al que está sirviendo la Iglesia, según ellos. Otrecl a Dios esta prueba de paciencia, ya que a mi se me culpó, en gran parte, del mal que pesa en el pals y en nuestra Iglesian (11 de agosto de 1979).

La división del episcopado aparece en el Diario alrededor de tres temas que se Irataron en las reuniones episcopales: la carta del clero en contra del nuncio, las elecciones de la CEDES y el tema mismo de la unidad de los obispos. Respecto al primer problema, Monseñor afirma en el Diario de su primera 
intención lue no asistir a la reunión de la CEDES porque, aparte de que la invilación se la hablan enviado sumamente larde, el diálogo era ya imposible. Al tinal lue, siguiendo el consejo de sus asesores, quienes le hablan indicado la conveniencia de estar presente dada la importancia del tema y la necesidad de que alguien defendiera a los sacerdotes, ya que Monseñor Rivera se encontraba fuera del pals. Sus temores no eran inlundados, cuando llegó a la reunión vio que todo "venia preparado." No se hizo caso de un telegrama de Monseñor Rivera en el cual pedía ser esperado para tratar el tema. Su propio reclamo en favor de la pelición de Monseñor Rivera no fue escuchado y, además, tuvo que protestar porque el documento que iban a publicar "ya venla trabajado. Me dijeron que siempre se presentaba un documento base, pero vela que aquello no era sólo un documenlo base, puesto que no se discutió sino que ya se comenzaba a firmar a pesar de decir yo mis razones en contra" ( 3 de abril de 1978).

Monseñor, lal como lo explica en el Diario, se oponla a publicar el documento preparado y no discutido, en el cual se defendla el nuncio y se condenaba al clero. porque dado que eran los sacerdotes quienes habían escrito al nuncio, ahora lo que correspondia era que "el nuncio invile a los sacerdotes a dialogar;" cuando los obispos acusaban a los sacerdoles en el documento preparado de faltar a la Santa Sede, Monseñor distingula "entre la Santa Sede, (representada) principalmente en la figura del Papa con el cual todos los sacerdoles se sienten unidos por la le, y la ligura del nuncio que represenla al Papa y que no siempre lo representa nítidamenle. Enfoqué a esle propósilo varias cosas que aqul y en Guatemala han hecho del señor nuncio una figura poco deseable;" porque el documento de los olros obispos insistía en las "expresiones inadecuadas" de los sacerdoles en vez de detenerse en el contenido de su carla, es decir, en la falta de testimonio cristiano del nuncio (en este sentido para Monseñor, la carta de los sacerdotes no era "tan condenable... ya que había que analizar loshechos a que se reliere esa carla, hechos que más bien invitan al señor nuncio a reflexionar para dar un testimonio más cristiano" (5 de abril de 1978); porque se estaba condenando a los sacerdotes sin haberlos oído y porque "publicar este documento era fomentar una división entre los obispos supusto que yo no estaba dispuesto a lirmar" (5 de abril de 1978). Su obispo auxiliar, Mons. Revelo respondió a esto último diciendo que no le imporlaba la división, sino cumplir con un deber.

Cuando la CEDES se mantuvo firme en su delerminación de publicar el documento, sus consullores le aconsejaron no hacer ninguna aclaración; la lalta de su firma era suliciente. Los senadores y otros asesores añadieron que el documento episcopal más bien despertarla la curiosidad por un texto que muchos desconoclan. La respuesta de los obispos, por otro lado, incurría en alaques de tipo personal contra los sacerdotes firmantes que estaban fuera de lugar y contribulan, en opinión de los asesores de Monseñor, a difamar al nuncio y a la jerarqula. El comenlario personal de Monseñor sobre el documento de los otros obispos fue el siguienle: "ha producido un ambiente muy desagradable contra los obispos ya que se considera como una imprudente manilestación de desunión" (5 de abril de 1978).

El 17 de julio de 1979 se reunieron todo el día para hacer las elecciones de la CEDES y tratar el tema del seminario. Monseñor escribió una carta antes de la 
reunión refiriéndose a la desunión y "suplicando" posponer la elección hasta que hubieran reflexionado profundamente sobre la unidad episcopal. Pero lue inútil, reconocieron culpas mutuas, pero no pasaron de ahl, pues como bien lo apuntó Monseñor en el Diario, la división tenla ralces personales y mucho de apasionamiento de parte de los otros obispos. Su resumen de la sesión fue el siguiente, "no pudimos sacar ninguna conclusión, pero hemos platicado bastante a fondo y creo que la tierra está removida para continuar..." (17 de julio de 1979).

En éecto, en repetidas ocasiones Monseñor suplicó a los demás miembros de la CEDES hacer un esfuerzo para construir la unidad alrededor del evangelio y del magisterio de la Iglesia. Es decir, no se trataba de cualquier forma de unidad ni de una unidad vacla de contenido. El método propuesto por Monseñor era el diálogo; pero tal como lo anola con preocupación en su observación del 17 de julio de 1979, los otros obispos le estaban exigiendo algo inaceplable desde el evangelio y desde el magisterio de la lglesia, "...me preocupa la radicalidad de algunos hermanos obispos contra mi actuación pastoral. La marcan con su deseo de que no siga adelante. Me da lástima pensar que no sean sensibles a la situación del pals y que sienlan más a gusto un pastoral, una predicación que no purífique, que no tienda a liberar a nuestro pueblo de esla lerrible situación" (17 de julio de 1979).

El 5 de noviembre de 1979, Monseñor visitó al nuncio, "...comentamos... la situación de los obispos. Le pedl que hiciera todo lo posible por impulsar nuestra unidad, pero a base de una reflexión seria de la situación del país. Me dio la razón y prometió hacer todo lo que está a su alcance" (5 de noviembre de 1979).

Dos semanas más tarde, nueva reunión de la CEDES para realizar las elecciones. El nuncio abrí́ la sesión con un saludo y luego los invitó a la unidad. Como una medida práctica les propuso crear una comisión integrada por Monseñor Rivera y Revelo para que mediara entre el arzobispo y los otros tres obispos de San Vicente, San Miguel y Santa Ana. Pero ni Monseñor Aparicio ni Monseñor Alvarez aceptaron la propuesta, "yo de mi parte, apoyé y dije que era conveniente nombrarla y que trabajara aun antes de proceder a unas elecciones que no estaba el ambiente propicio para eso, dado que estábamos polarizados y no habrla una posibilidad de que las elecciones unieran, sino más bien agrietaran más nuestra unidad" (19 de noviembre de 1979).

En estas condiciones se procedió a elegir, lo cual "resultó muy parcial, muy arbitrario el proceder... la mayoría, Aparicio, Alvarez, Revelo y Barrera hicieron lo que quisieron con la votación." Monseñor Alvarez resultó electo presidenle, pero hubo anomallas canónicas sobre las cuales Monseñor escribió una carta al nuncio. Consecuentemente los demás cargos importantes de la CEDES se los distribuyeron de acuerdo con la mayoría, para lo cual, además, el nuevo presidente, Monseñor Alvarez, utilizó el doble voto. Monseñor escribió al nuncio relatando todo este arbitrario y poco canónico proceder y proponiendo dar la presidencia de la conlerencia a Monseñor Rivera, a quien le perlenecla canónicamente. Para Monseñor, además, era la "persona más indicada como más conciliatorio para poder fomentar la unidad, asl $\infty$ mo también más prudente e inteligente para dar un nuevo rostro a una conferencia que está muy desprestigiada y que se desprestigiará más con la presidencia de un obispo marcadamente señalado por su posición polltica social en el gobierno anterior y por su imprudencia en criterios y 
superficialidad en juicios... Espero que mi carta sea alendida, pero por lo menos, quedará constancia de mi inconformidad con este proceder" (19 de noviembre de 1979).

La ilegalidad de las elecciones trajo cola. El 2 de diciembre de ese mismo año, con motivo de celebrarse los 25 años de la dí́cesis de Santiago de Marla los obispos se volvieron a reunir en dicha ciudad. Monseñor llegó la tarde anterior y durante la noche "compartió en intimidad" con Monseñor Rivera los sucesos anteriores. Después de la concelebración del dla 2, Monseñor Alvarez convoco de urgencia a la CEDES para aclarar las dudas existentes sobre su elección como presidente. Monseñor les informó de su carta al nuncio. Monseñor Aparicio invocó una ilegalidad a su favor. En cambio, Monseñor reclamó la presidencia para Monseñor Rivera, pero también propuso "pro bono pacis, se dejaran las cosas como están, pero que conslara nuestra propuesta. Después de una discusión que me dejó como siempre, amargado en mis relaciones con la conferencia episcopal, ya que se nota una inquina personal hacia ml, sin embargo, ofreciéndole todo al Señor, fui a la celebración de una reunión al colegio Santa Gema de Aludani, donde se nos dio también un simpático almuerzo" (2 de diciembre de 1979).

A estas alturas volvió a intervenir el nuncio, quien convocó a los obispos el19 de febrero de 1980, para inlormarles que la congregación de obispos habla declarado inválidas las elecciones. Se les pedla a los obispos que reflexionaran y oraran primero, antes de volver a hacer las elecciones. El nuncio, por lo tanto, les propuso una reunión de un dla a principios de marzo, la mañana la dedicarlan a la oración y la reflexión y en la tarde se repetirlan las elecciones. De este encuentro Monseñor observó que "ninguno de mis hermanos obispos mencionó el asunto (una bomba habla explotado en el transmisor de la YSAX)... asl como nadie se refirió a mi doctorado honoris causa, ni a las circunstancias de nuestra arquidiocesis, más que para criticar, siempre como si fuera desviada de su camino pastoral." Después de la sesión, el nuncio los invitó a almorzar. La impresión general de Monseñor fue la siguiente, "el ambiente de esta reunión siempre me resulta muy frío y muy raro, opté por no decir palabra alguna, ya que todo cuanto se dice es mal interpretado por la mala voluntad que existe, sin duda, en algunos hermanos obispos" (19 de febrero de 1980).

En marzo de 1980 intervino el nuncio de Costa Rica, quien fue enviado por Roma para unir al episcopado. El nuncio entregó a Monseñor una carta del cardenal secretario de Estado en la cual le volvlan a pedir su colaboración, casi como si él fuera quien no deseaba la unidad del episcopado y fuera el principal estorbo para la unidad. En esta entrevista ambos comentaron varios aspectos de la desunión. Monseñor trató de explicar al nuncio su posición al respecto, "él hizo varias observaciones y traté de convencerlo de mis convicciones, en conciencia; pero nolo en él cierta prevención contra mi proceder y a pesar de explicarle el ambienle tan diflcil en que nos movemos y la aceptación que el pueblo tiene a esta linea, el mantiene ciertos temores de que las organizaciones populares sean comunistas y, este aspecto y lemor del comunismo, es el que invade algunos de sus juicios. Yo le dije que lenla yo mucho cuidado de evitar esas infiltraciones y que era una de mis preocupaciones y que no tuviera cuidado de que mi apoyo a la organización populàr significara simpatla por la izquierda, ni mucho menos la ignorancia del peligro de infiltración, que con toda franqueza reconozco, pero que 
también veo que el anti-comunismo entre nosotros es muchas veces el arma que usan los poderes económicos y políticos para sus injusticias sociales y políticas. Creo que ha quedado clara la idea de mi posición y aceplo, desde luego, que en todas aquellas cosas accidentales en que se puede ceder, estoy dispuesto a ceder por el bien de la Iglesia y de mi querido pueblo" (11 de marzo de 1980).

El 12 de marzo se tuvo la reunión anunciada antes en la casa de ejercicios espirituales de Ayagualo (en las afueras de Santa Tecla). El nuncio de Costa Rica les dijo la misa, después promovió un diálogo entre las dos partes de la conlerencia, "por mi parte expresé que era mi ałán de tidelidad del evangelio y a la doctrina de la Iglesia, la cual siempre resulta conflicliva cuando se la aprueba, no sólo en teorla, sino cuando se trata de vivir y también señalé que estas divisiones ya eran en tiempo de Monseñor Chávez y que era siempre como una crílica contra la arquidiócesis que trata de ser fiel a estas IIneas de la Iglesia post-conciliar. También dije que se hacla mucha crítica del arzobispado y no se ofreclan ejemplos vivos de las otras diócesis para imitarlos y que lo que yo pedía era un respelo para la arquidiócesis y que respetáramos también cada uno su propia jurisdicción. También Monseñor Rivera esluvo muy inteligenle con más datos precisos, históricos y doctrinales, al proceder de nuestra arquidiócesis a partir del Concilio... Las otras intervenciones de los olros obispos, naturalmente iban contra la linea del arzobispado y se sacaron muchos argumentos superficiales, aunque reconozco aquellas cosas en que puede haber un error de mi parte y estoy dispuesto a corregir" (12 de marzo de 1980). La discusión se prolongó hasta las cuatro de la tarde, cuando se procedió a las elecciones.

Los demás obispos aceptaron la propuesta de Monseñor de unirse eligiendo a Monseñor Alvarez como presidente de la CEDES, asl se dejaban las cosas como estaban y se ratílicaba la primera elección. Pero lo sorprendieron al elegir al vice-presidente. La vicepresidencia le correspondla a Monseñor Rivera, pero los demás obispos eligieron a Monseñor Aparicio, "me ha quedado una gran inquielud por esta incoherencia de nuestros propósitos de unidad" (12 de marzo de 1980).

Finalmente, también acordaron publicar un documento conjunto sobre la situación del país, como un signo de la unidad del episcopado, y consultarse mutuamente cuando alguno hiciera declaraciones que afectaran a los demás, "comprendl que se trataba de mi caso personalmente, pero también dije que aceplaba eslas condiciones, toda vez que también tuvieran en cuenta las declaraciones que muchas veces se hacen en otras diócesis con mucha imprudencia y que compromelen también a la lglesia" (12 de marzo de 1980).

A pesar de todo, Monseñor concluyó que la reunión de la CEDES habla sido "muy frucluosa," aunque no sin razón temla "dada la agresividad con que me atacaron Monseñor Aparicio y Monseñor Alvarez de que no se haya ganado mucho en sentimientos prolundos de unidad. El Señor dirá y de mi parte quiero olrecerle lodos estos sacrificios y sinsabores a fin de que prevalezca el evangelio y lodos nos convirtamos a la verdad y al servicio de Dios y de nuestro pueblon (12 de marzo de 1980).

A lo largo de estas relaciones de las sesiones de la CEDES queda manifiesta la buena voluntad de Monseñor; querla y sutrla por la unidad, estaba dispuesto a ceder siempre que ello no supusiera abandonar el evangelio, el ma- 
gisterio o al pueblo. Sufría y temla porque era bien consciente de que de por medio estaban más bien apasionadas razones personales que imposibilitaban el diálogo sereno y franco. Siempre que aparecen estos problemas en el Diario, Monseñor añade que tiene "la mejor buena voluntad y con la gracia de Dios haré lo que pueda por esta unificación, que yo soy el primero en sentir cuánto mal hace en nuestro ambienlen (2 de julio de 1979). Sus razonados temores no lo llevaron, por otra parte, a perder la esperanza. Asl, después de desayunar con los colaboradores de la curia para discutir la marcha del arzobispado, comentó que habia salido "muy conlento porque es una esperanza y una alegría ver que Monseñor Revelo se está tratando de incorporar a nuestro trabajo en equipo y a ver la siluación real de nuestra arquidiocesis" (15 de abril de 1978). Al linal, la integración no fue posible, pues Monseñor Revelo llegó a sobrepasar sus lacultades, pasando por encima de la autoridad del arzobispo al cambiar los estatutos de CARITAS arquidiocesana, por iniciativa del presidenle nacional de la inslitución, Monseñor Aparicio (14 de noviembre de 1978).

Durante la primera junta de gobierno, Monseñor aprovechó su amistad con el canciller para pedirle que informara al Vaticano de lo que estaba ocurriendo en la CEDES y que como cristiano pidiera a Roma una colaboración expllcila para implementar las líneas trazadas por Medellin y Puebla y "en este sentido le hablé francamente de las actitudes del señor nuncio y de ciertos obispos que están muy lejos de esta linea pastoral." De la misma manera, Monseñor pidió al canciller solicitar una mejor orientación de la vicaría castrense, "que ha estado sin funcionar como debla ser en su carácter pasloral," y él to sabia bien por experiencia y por sus conlactos intensos con los mililares; e informar de las estrechas relaciones de estos obispos con "la clase dirigente económica" y de la desunión entre ellos ( 3 de diciembre de 1979). El canciller respondió positivamente a estas inquietudes de Monseñor y conversaron sobre la oportunidad de enviar una misión especial a Roma, pero obviamente ya no hubo tiempo para ello. El 20 de diciembre, cuando Monseñor se volvió a enlrevistar con el canciller para conversar sobre el mismo tema, éste le advirtió que la nunciatura le habla expresado que "no hay esperanza de cambios en este sentido" (20 de diciembre de 1979).

A Monseñor le maravillaba esta situación de los obispos salvadoreños cuando comparaba "como en otros palses se comprende con mucho cariño este trabajo de tanlo sacrificio, mientras interiormente, mis hermanos obispos parecen tan incomprensivos de este trabajo que, sinceramente, quiere ser un servicio a Dios y al evangelio. ¡Pido al Espirítu Santo que me haga caminar por los caminos de la verdad y que nunca me deje llevar ni por los halagos ni por los temores de ofender a nadie más que a Nuestro Señor!" (13 de marzo de 1980).

El nuncio de Costa Rica, sin embargo, enviado a promover la unidad, tracasó, en parte porque se parcializó pronto, según la interprelación de Monseñor. No fue capaz de comprender la dillcil siluación en que estaba. En la última referencia que se encuenlra en el Diario, del 13 de marzo de 1980, decla notar en el nuncio "siempre una predisposición." Sus últimas recomendaciones a Monseñor fueron las siguientes, "siempre en el senlido de que soy yo el bastante culpable de la desunión de los obispos, a pesar de mis sugerencias de recordarle la reunión de ayer (la última de las elecciones) y que él tuvo que reconocer que 
habla bastante apasionamiento, sobre todo en Monseñor Alvarez y Monseñor Aparicio. No obstante reconocer este apasionamiento y ese aspecto personal contra ml, él insiste en que debo ceder hasta donde sea posible, lo cual es también mi pensamiento, pero no en lo sustancial cuando se trata de ser fiel al evangelio, a la doctrina de la lglesia y sobre todo a este pueblo tan sulrido que cuesta que lo comprendan" (13 de marzo de 1980).

\section{Tres visitas a Roma a Inlormar}

En el Diario, Monseñor relata tres visitas a Roma, la primera a finales de junio de 1978, la segunda a principios de mayo de 1979 y la tercera a finales de enero de 1980. En las tres visitas explica que fue a Roma a dar personalmente informes objetivos contra supuestas acusaciones en su contra; eran esfuerzos por Iratar de que comprendieran al pueblo salvadoreño y a su pastor.

Según el testimonio del Diario, el primer viaje fue aconsejado por sus asesores ante los rumores que estaban corriendo de que una comisión del gobierno y de la oligarqula irla a Roma a mal informar del arzobispo y a pedir su deslitución. El senado le aconsejó preparar unos buenos informes y valerse de experimentados intermediarios en las esferas romanas para neulralizar los de la nuncialura, del gobierno y del capital (12 de abril de 1978). Por olro lado, el 24 de mayo recibió una carta de la congregación de obispos invitándolo a dialogar sobre la situación de la arquidiócesis. De inmediato consultó sobre la oportunidad del viaje con sus más Intimos asesores, quienes unánimemente le recomendaron ir "para esclarecer con la sinceridad y buena voluntad con que lo voy haciendo el trabajo pastoral de esta arquidiócesis" (24 de mayo de 1978). El 10 de junio, el objelivo del viaje tal como aparece en el Diario era "para rendir cuentas de nuestra situación ante la Santa Sede" (10 de junio de 1978).

El segundo viaje fue pagado por las religiosas dominicas de la arquidiócesis en calidad de invitado especial a la bealificación del fundador de la congregación, Francisco Coll. Sin embargo, Monseñor se preparó bien recopilando documentos y testimonios de solidaridad con la arquidiócesis, "pero voy más bien a escuchar ya que se han dado bastantes informes de nuestra situación" (26 de abril de 1979).

EJ último viaje tuvo las mismas caracterlsticas de los dos anteriores, llevar informes objetivos para contrarrestar "cualquier parcialidad que allá hubiera" (14 de enero de 1980). Esta visita a Roma la hizo aprovechando que habla aceptado ir a Lovaina a recoger el doctorado ofrecido por aquella universidad.

Roma siempre significo para Monseñor algo muy especial, una ciudad de fuertes emociones y de recuerdos de juventud muy queridos, de los cuales dejó testimonios elocuentes en su Diario. En los tres viajes lo primero que hizo, después de descansar un poco, fue ir a visitar la tumba de San Pedro, njunto a la tumba del primer Papa he orado inmensamente por la unidad de la lglesia... pero especialmente por nuestra arquidiócesis, encomendándole a San Pedro los intereses de nuestra lglesia y el éxito de este diálogo con la Santa Sede..." (16 de junio de 1978). Después, como se tralaba de una visita ad limina, a la cual lue acompañado de Monseñor Rivera, fue a San Pablo exira muros, "de rodillas junto a la tumba del apósiol de los gentiles del gran San Pablo. En aquel ambienle de oración, casi de cielo, he sentido revivir en mi memoria, en mi corazón, en mi amor todas aquellas emociones de mis tiempos de estudiante $-\mathrm{y}$ de sacerdote-... 
siempre han sido mis oraciones ante estas tumbas de los aposioles inspiración y fortaleza, sobre todo esta tarde en que siento que mi visita no es una simple visita de piedad privada, sino que en el cumplimiento de la visita ad limina, traigo conmigo, todos los intereses, preocupaciones, problemas, esperanzas, proyectos, angustias de todos mis sacerdotes, comunidades religiosas, parroquias, comunidades de base, es decir, de toda una arquidiocesis que viene conmigo a postrarse como ayer ante la tumba de San Pedro, hoy ante la tumba de San Pablo" (17 de junio de 1978). Finalmente, la visita a San Juan de Letrán, el 24 de junio de 1978, la que "me trajo tantos recuerdos aquel coro y aquel órgano y aquella iluminación en que relulgen los mosaicos de la vieja basilica. Y aquella muchedumbre, la humanidad actual, que se mueve a través de siglos, en un presente siempre actual en la Iglesia. Un momento para reflexionar y entusiasmarse y ser humilde tiel servidor de la Iglesia" (24 de junio de 1978).

En el segundo viaje habló de Roma como de una ciudad donde era muy dichoso porque estar en ella era una bendición del Señor. He aqul su descripción del amanecer del 29 de abril en la ciudad eterna, "iste amanecer en Roma evoca tantos recuerdosl Estos paisajes que yo conocl cuando estudiaba mi teologla, cuando me ordené sacerdote y vivl mis primeros meses sacerdotales, es una renovación para mi espíritu. Ahora con nuevas responsabilidades, siento que Roma es una bendición del Señor que confirma mi misión, mi trabajo, que Dios comparte dándome esa dicha de poder colaborar humildemente en la implantación de su reino en el mundo" (29 de abril de 1979). Al visitar la tumba de San Pedro pidió mucho "la lidelidad de mi le cristiana y el valor, si fuera necesario, de morir como murieron todos eslos mártires o de vivir consagrando mi vida como la consagraron estos modernos sucesores de Pedro. Me ha impresionado más que todas las tumbas, la sencillez de la tumba del Papa Pablo VI" (3 de mayo de 1979).

El 28 de enero volvió a Roma por tercera vez con la emoción de siempre, -Roma significa para mi volver a la cuna, al hogar, a la fuente, al corazón, al cerebro de nuestra lglesia. Le he pedido al Señor que me conserve esta fe y esta adhesión a la Roma que Cristo ha escogido para ser la sede del pastor universal... y nuestra primera visita, después de almorzar, fue a la basilica de San Pedro. El recorrido que siempre me ha gustado hacer, la visita al Santlsimo, la visita a la tumba del apóstol San Pedro, a la tumba de San Plo X y a las tumbas de los papas, donde sentl especial emoción al orar junto a la tumba de Pablo VI, de quien estuve recordando tantas cosas de sus diálogos conmigo, en las visitas que tuve el honor y la dicha de ser admitido a su presencia privada" (28 de enero de 1980).

Indudablemente, el momento cumbre de las tres visitas fue su entrevista privada con el Papa. En su primer viaje lue recibido, junto con Monseñor Rivera, por Pablo VI, quien le inspiraba mucha contianza y por quien sintio mucha admiración, "...nos da mucha contianza de encontrar en Roma un paslor de la lglesia con lanta experiencia, con tanta sabidurla y, sobre todo, con tanto amor a Dios y a la humanidad" (16 de junio de 197e). La mañana de la audiencia, el 21 de junio, la califico de inolvidable, de un momento emocionante. He aqul la descripción de esos momentos tan importantes para Monseñor en los cuales vio confirmada su fe y su servicio al evangelio y al pueblo salvadoreño. "El Papa nos hizo sentar a un lado y a otro de él y dirigiéndose a ml en particular, me estrechó la mano derecha y me la retuvo entre su dos manos largo rato, yo también estreché con mis dos 
manos las manos del Papa. Hubiera querido para ese momento una fotografla que expresara esa Intima comunión de un obispo con el centro de la unidad católica. Y teniéndome asi las manos, me habló largamente. Me sería difícil repetir al pie de la letra su largo mensaje, porque, además de no ser esquemático, sino más bien cordial, amplio, generoso, la emoción del momento no es para recordar palabra por palabra. Pero las ideas dominantes de esas palabras fueron éstas: comprendo su dificil trabajo. Es un trabajo que puede ser no comprendido, necesita tener mucha paciencia y mucha fortaleza. Ya sé que no todos piensan como usted. Es difícil en las circunstancias de su pals tener esa unanimidad de pensamiento. Sin embargo, proceda con ánimo, con paciencia, con fuerza, con esperanza. Me prometió que rezarla mucho por ml y por mi diócesis. Y que hiciera todo esiuerzo por la unidad. Que si en algo podía él personalmente servir que con gusto lo harla. Se refirió luego al pueblo... que hoy sufre mucho y busca sus reivindicaciones. Me dijo que habla que ayudarlo, trabajar por él, pero jamás con odio, lomentando las violencias, sino a base de un gran amor. De hacerle sentir el valor de su sufrimiento, de predicar la paz... Habló lambién de las díticullades que solamente se pueden superar con el amor; dificultades con las fuerzas dominanles, dílicultades con colaboradores, que no todos comprenden el esfuerzo que se hace... siento no haber recordado más las palabras, pero sustancialmente fueron las que he mencionado. A $\mathrm{ml}$ me dejó la satisfacción de una confirmación en mi fe, en mi servicio, en mi alegrla de trabajar y sufrir con Crislo, por la Iglesia y por nuestro pueblo. Creo que este sólo momento bastarla para pagar todo esfuerzo de venir a Roma..." (21 de junio de 1978).

En su segundo viaje le lue más diflcil tener acceso directo al Papa, esta vez, Juan Pablo II. El 30 de abril pidió la audiencia, pero no le dieron ninguna respuesta. El 2 de mayo se encontró con el papa en la audiencia general, después de impantir la bendición a los asistentes con los demás obispos visitantes. Al estrecharle la mano y pedirle la bendición para la arquidiócesis, "él me dijo que tendrlamos que platicar en privado, lo cual, le dije que era mi mayor deseo..." Cuando volvió a pedir la audiencia se la prometieron hasta dentro de una semana, "insistiré porque es mi mayor deseo y mi mayor necesidad de conversar con el Papa." EJ 3 de mayo explicó al responsable de conceder las audiencias "la urgencia de ver al Papa dada la siluación de mi diócesis y mi situación de estar tan lejos y querer aprovechar el liempo en otros asuntos también. Sin embargo, caigo en la cuenta y he de tener paciencia para esperar mi turno" (3 de mayo de 1979). Al dla siguiente volvió a buscar una respuesta sin encontrar ninguna aún, lo cual "no ha dejado de preocuparme mucho esta actitud para con un pastor de una diocesis...," pero de inmediato ańadió, "lo he dejado todo en manos de Dios diciéndole que, de mi parte, he hecho todo lo posible y que, a pesar de todo, creo y amo a la Santa Iglesia y seré siempre tiel, con su gracia, a la Santa Sede, al magisterio del Papa y que comprendo la parte humana, limitada, delectuosa de su Santa Iglesia que siempre es el instrumento de salvación de la humanidad y a la cual quiero servir sin ninguna reserva" (4 de mayo de 1979). El 5 de mayo le dieron respuesta, estarla con el Papa dos dlas más tarde, el 7 de mayo.

Ese dla, amaneció preparando los documentos que presentarla al Papa durante la audiencia, cuatro intormes de comisiones extranjeras que habian visitado el pals y en los cuales presentaban la situación, "se trata de documentos 
de solidaridad, de denuncia, también de mi postulación al premio Nobel y otros..." También llevaba una carta enviada al Papa en noviembre, pero que dudaba de si la habla recibido. Juan Pablo II lo recibió a las 12:20 en audiencia privada y le ofreció una silla, "...comenzó a preguntarme de la situación del pals. Le invité atentamente a que siguiéramos el memorándum que llevaba escrito, a lo cual él accedí́ gustoso. Comenzamos a leer y yo le iba sacando documentos. Cuando saqué la carpeta de las informaciones extranjeras sobre la situación del país se sonrió viendo que era un volumen muy grueso y que no habrla liempo de verlo. Yo le pedí disculoas y le dije que era para que ordenara un estudio y que le dieran un resumen, pero que a mi me interesaba que luviera una idea de cómo criterios imparciales bosquejan la situación de injusticia y de atropello que hay en nuestro pals. Le di también un folder con el retrato del Padre Octavio, muerto, y mucha información sobre ese asesinato."

Después de entregarle con una breve explicación cada una de las siele carpelas que llevaba preparadas, "el Papa comenzó a comentar de acuerdo con el último punto del memorándum, que se relerla a un diálogo en búsqueda sincera del pensamiento del Papa y de un mejor servicio a nuestro pueblo. Conlesó que es muy diflcil una labor pastoral en el ambiente político en que me toca actuar. Recomendó mucho equilibrio y prudencia, sobre todo, porque era riesgoso caer en errores o equivociaciones al hacer las denuncias concrelas. Yo le aclaré y él me dio razón de que hay circunstancias. Le cité, por ejemplo, el caso del Padre Octavio, en que se tiene que ser muy concreto porque la injuslicia, el atropello ha sido muy concreto. Me recordó su situación en Polonia, donde tuvo que hacer trente a un gobierno no calólico y con el cual había que desarrollar la lglesia a pesar de las dificultades. Le dio mucha importancia a la unión del episcopado; volviendo a recordar su tiempo en Polonia, dijo que esle era el problema principal, mantener la unidad episcopal. Le aclaré también que yo era lo que más deseaba, pero que tenla en cuenta que una unión no tiene que ser fingida, sino sobre el evangelio y la verdad."

El siguiente tema fue el de la úlima visita apostólica que habla mandado hacer en la arquidiócesis. A continuación invitó a Monseñor a tomarse la folo y le regaló objetos piadosos. La impresión general de esta audiencia fue la siguiente. - Yo sali complacido de este encuenlro, pero preocupado por advertir que influia una información negaliva acerca de mi pastoral, aunque en el fondo recordé que habla recomendado audacia y valor, pero al mismo tiempo, mensurada por una prudencia y un equilibrio necesario. Aunque mi impresión no lue del todo satisfacloria, a primera vista, creo que ha sido una visita y una entrevista sumamente útil ya que he sido tranco y yo he aprendido que no se debe esperar siempre una aprobación rotunda, sino que es más útil recibir advertencias que pueden mejorar nuestro trabajo" (7 de mayo de 1979).

En su tercer viaje, el primer encuentro con el Papa también ocurrió en la audiencia general del 30 de enero de 1980. En esta ocasión "yo luve la dicha de quedar directamente a su derecha y después cuando saludábamos al Papa los obispos, me dijo que después de la audiencia querla hablar especialmente conmigo, pero luve que esperar todavla un buen rato..." porque después del saludo a los obispos comenzó la actuación de un circo y de un coro polaco al cual saludó delenidamenle. 
En el Diario, Monseñor dice que el Papa lo recibió "con mucho cariño. Me dijo que comprendla perfectamente lo diflcil de la situación polltica de mi patria y que le preocupaba el papel de la lglesia. Que tuviéramos en cuenta no sólo la defensa de la justicia social y el amor a los pobres, sino también lo que podrla ser el resultado de un esfuerzo reivindicativo popular de izquierda, que puede dar por resultado también un mal para la lglesia. Yo le dije, Sanlo Padre, precisamente es ese el equilibrio que yo trato de guardar, porque por una parte, defiendo la justicia social, los derechos humanos, el amor al projimo pobre, y por otra parte, siempre me preocupa también el papel de la Iglesia y el que no por defender eslos derechos humanos vayamos a caer en unas ideologlas que destruyen los sentimientos y los valores humanos. Que estaba muy de acuerdo con sus discursos y que esos discursos me daban mucha fuerza y argumento para mi actuación y predicación... El Papa sentl que eslaba muy de acuerdo en todo lo que yo le decla y al terminar me dio un abrazo fraternal y me dijo que rezaba lodos los días por El Salvador. Yo he sentido aqul la confirmación y la fuerza de Dios para mi pobre ministerio..." (30 de enero de 1980).

Después de las entrevistas con el Papa estaban las congregaciones romanas, "pero la palabra de él (el Papa) es la básica en esta comunión, es una palabra de esperanza, de alienlo... me ha conlirmado en mi voluntad de servir con amor a nuestro pueblo desde la lglesia de Jesucristo" (21 de junio de 1978). A este nivel de las congregaciones le interesaban tres en concreto, la congregación de obispos, la de educación y la secretarla de Estado. En sus tres visitas se entrevistó, pero por motivos personales, con el cardenal prefecto de la congregación de religiosos, el cardenal Pironio. No cabe duda que además estuvo en otras congregaciones, pero a éstas no las menciona en el Diario.

En su primera visita, al llegar a la congregación de obispos, lo recibió un monseñor con quien conversó, junto con Monseñor Rivera, pero obteniendo muy poco resultado porque *...hemos notado en su mentalidad una serie de conceptos y prejuicios que nos han dejado muy poca esperanza para comprender la pastoral" arquidiocesana. Pese a ello, "la plática ha sido muy útil", aunque casi no los dejó hablar, "ya que casi sólo él hablaba" (19 de junio de 1978). Con el cardenal Baggio le fue un poco mejor, pues crela que habla logrado desvirtuar "muchas informaciones que no son exactas y que, más bien, proceden de intereses contrarios a los que tralo de delender..." (20 de junio de 1978).

En el segundo viaje, antes de entrevistarse con el cardenal Baggio, tue primero a la basilica de San Pedro "para encomendarme a los grandes pontífices, que reposan en las criptas del Vaticano y que han dado tanta inspiración y orientación a mi vida y sostener este momento de recogimiento para luego ir a hablar de cosas muy importantes a la congregación..." (7 de mayo de 1979). La audiencia la encontró cordial, quizás porque "esperaba un poco de severidad como la vez anterior, el ańo pasado." Según afirma en el Diario, el cardenal Baggio deseaba encontrarse con él. El prelecto de la congregación de obispos le insislió en la división del episcopado, en la situación de su auxiliar, "traté de explicarle toda esta siluación porque, además, advert que, entre las causales que habia puesto Monseñor Revelo para este acto (cambiar los estalutos de CARITAS sin consultar al arzobispo) estaba el que CARITAS se politizaba y cala en manos de guerrilleros..." Luego conversaron sobre la recomendación del visitador apostólico, un arzobispo 
de Argentina, quien habla sugerido designar un administrador apostólico con sede plena. Monseñor se opuso a esta sugerencia porque le parecla algo ineficaz y muy dañino para la diócesis. No se tralaba únicamente de resolver problemas personales, sino de que la voz del obispo es la expresión de todo un pueblo, lo cual quedarla completamente anulado con un administrador apostólico con sede plena, "cualquiera comprenderla que es una desconlianza acerca del propio obispo" (28 de mayo de 1979). En cambio, Monseñor sugirib al cardenal prefecto una solución más radical, la nominación de nuevos obispos con criterios del Vaticano II. "para inyectar nuevos criterios a la conferencia episcopal, evitando asi una desunión que no tiene razón de ser ya que va en contra de los principios del concilio" (28 de mayo de 1979). En su conversación, Monsefior manifestó su "mejor voluntad de arreglar las cosas en lo que a mi capacidad permita." Entonces, el cardenal reacciono, "de forma muy cordial," cuando le dijo, "no estamos tratando entre enemigos, sino entre trabajadores de la misma causa y estamos, desde luego, en un noventa por ciento de acuerdo. Y es asI que el ciento por ciento es la verdad y es el evangelio." Monseñor respondió diciendo que le "daba mucho ánimo esa palabra... encontraba aqul, en la plática con él, una esperanza de que mi situación y la de mi diócesis tiene solución si la seguimos buscando con la buena voluntad y amor a la lglesia." La última impresión de Monseñor fue que el cardenal "parecla bastante satisfecho." El también salió satistecho de la entrevista (8 de mayo de 1979).

En la última visila no lo pudo atender personalmente el cardenal Baggio, sino uno uno de sus asistentes quien se mostró "muy comprensivo." Le dejó copia de una carta que habla escrito al cardenal Lorscheider, el segundo visitador aposiólico, mencionado en el Diario, donde resumla sus conversaciones en San Salvador. Le encomendó mucho resolverle el asunto pendiente acerca del obispo auxiliar y la renovación de la conferencia episcopal "con nuevos elementos, abiertos a las nuevas mentalidades de la lglesia" (30 de enero de 1980).

La siguiente congregación que le preocupaba bastante era la de la educación, por el asunto del seminario. En electo, el 22 de junio de 1978, estando presente el cardenal prefecto y otros funcionarios hizo, Junto con Monseñor Rivera, sus aclaraciones sobre el seminario, lo cual fue muy útil porque habla muchas tergiversaciones de la verdad acerca de las relaciones entre el arzobispado, la curia y el funcionamiento del seminario." En la conversación "nos dimos cuenla de cosas muy desagradables que se han inlormado a espaldas de de nosotros. Y hasta se habla llegado a pedir una visila apostólica al seminario y al arzobispado." Al tinal, los dos obispos esperaban que "después de estas aclaraciones se tenga un mejor respeto de la vida de la curia arzobispal." Al menos ahora la congregación "pudo quedar bien informada de nuestra buena voluntad y de las dificultades, a veces de emergencia, que surgen en la vida de la diócesis y que afectan, naturalmente, al seminario..." (22 de junio de 1978).

En el tercer viaje tuvo mejor suerte en esta congregación porque se enconlró con el subsecretario, quien tenla "una mentalidad más abierta a los progresos que, muchas veces, escandalizan el tradicionalismo de nuestra Iglesia y me expresó, en forma muy confidencial, cuánto temla él por esa lalta de apertura de la lglesia. Se alegró de encontrar criterios parecidos en ml y conversamos ampliamente de la situación del seminario y me prometio hacer todo lo 
posible de conseguir lo más que pudiera y que me iba a comunicar. Me exhorló a tener ánimo y a tener en cuenta que, quien sigue esta línea progresisla de una Iglesia auténticamenle fiel a los postulados del Vaticano II, liene que sulrir mucho y ser tenido también en perspectivas sospechosas, pero que la conciencia y la satisfacción de servir a Dios y a la lglesia valía por encima de todas las persecuciones" (30 de enero de 1980).

En este último viaje relata una audiencia con el cardenal secretario de Estado, quien lo recibió "muy cordialmente y le preguntó sobre la situación del pals y el papel de la Iglesia. El cardenal Casaroli también se preocupó por los derechos humanos, las reivindicaciones del pueblo, pero advirliendo que éslas no lueran a suponer "una hipoteca de la lglesia y de los sentimientos crislianos ante las ideologías, de lo cual le dije, como ayer al Santo Padre, que era también mi preocupación de predicar la justicia social, la defensa de los derechos humanos, pero al mismo tiempo advertir a las fuerzas populares reivindicadoras el peligro de caer en ideologlas extrañas. Le expliqué lambién que no podíamos hablar de anti-comunismo sin el peligro de que nos quisieran hacer cómplices de las injusticias de los ricos, que hablan del anti-comunismo, pero no por defender principios cristianos, sino por delender sus intereses materialistas. Yo nolé que el señor cardenal quedó satislecho de nueslra conversación y me aseguró que oraba también mucho por El Salvador" (31 de enero de 1980).

Además, Monseñor dejó lestimonio en el Diario de "como el cardenal vela que era justa mi perspectiva, de que habla que procurar salvar lo sano que hay en el actual gobierno y unirlo con lo sano que puede haber en los esluerzos y apoyos populares. Me dijo que él crela que ésa era la verdadera salida de nuestra crisis. Lo cual me contirmó mucho en seguir detendiendo la parte sana del gobiero y esforzarla a que encuentre un diálogo con las bases populares, a las cuales también hay que advertirles de su peligro de perder los sentimientos cristianos por una liberación lemporalista" (31 de enero de 1980).

A nivel de las congregaciones, sin embargo, sus mayores consuelos personales los encontró con el cardenal Pironio, "un gran amigo" quien a pesar de ser cardenal manlenla siempre "un esplritu de sencillez y humildad, de amistosa acogida" (26 de junio de 1978). Al despedirse, después de haber conversado cordialmente, cuando Monseñor le contó cómo lo acusan de ser inslrumento del comunismo, "me dijo, no me extraña puesto que hasta a mí me han publicado con el lítulo de 'Pironio pirómano.' Entonces es herencia de todos los que quieren predicar la justicia social y la promoción de nuestra América Lalina" (26 de junio de 1978).

En su segunda visila la conversación fue igualmente cordial y amistosa, tanto "que este sólo encuentro bastaba para colmarme de consuelo y de ánimo. Le expuse confidencialmente mi situación en mi diócesis y ante la Santa Sede. Me abrió su corazón diciéndome lo que él también tenia que sulrir, cómo siente profundamente los problemas de América Latina y que no sean del todo compren. didos... y sin embargo, hay que seguir trabajando, iniormando lo más que se pueda, la verdad de nuestra realidad. $Y$ me dijo, lo peor que puedes hacer es desanimarte, ¡Animo Romero! me dijo muchas veces" (9 de mayo de 1979).

La tercera entrevista también tuvo su novedad y su importancia. El cardenal Pironio eslaba ansioso de compartir con Monseñor los resultados de la visi- 
ta apostólica del cardenal Lorscheider, la cual "habla sido muy positiva y el Papa mismo tenía un intorme muy bueno acerca de ml. El cardenal Lorscheider le habla dicho al cardenal Pironio que yo tenía razón en El Salvador, que la cosa era muy dificil y que era yo quien miraba claro las circunstancias y el papel de la Iglesia y que habla que ayudarme. Supongo que esto es una sintesis de lo que platicó acerca de su viaje... Le agradecl mucho al cardenal Pironio y también lo animé, también porque él también me dijo que sulrla mucho, precisamente por este estuerzo en tavor de los pueblos de América Latina... Me recordó una frase del evangelio que él le da una aplicación especial, 'no temáis a los que matan el cuerpo, pero nada pueden hacer con el esplritu.' El lo interpreta que si los que matan el cuerpo son terribles, son más terribles los que acribillan el espiritu calumniado, difamado, destruyendo a una persona y él crela que éste era precisamente mi martirio, aun dentro de la misma Iglesia y que tuviera ánimo. El resumen lue un aliento muy poderoso que luego me preparó para ir más alegre a la entrevista con el Santo Padre en la audiencia general..." (30 de enero de 1980).

En el Diario hay además toda una serie de delalles que revelan mucho de la personalidad de Monseñor, durante sus estancias en Roma. Asi, por ejemplo, le gustaba asistir a las audiencias generales "confundido entre el pueblo," sintiéndose "uno de aquellos cristianos, que venidos de diversas naciones del mundo esperan con tanta ansia ver al Papa" (28 de junio de 1978). Sin embargo, en su último viaje, su visión de las audiencias generales fue más crítica, "la gente acogla con fervor y aplausos (al Papa). Pero en la periferia, donde yo me encontraba habla mucha distracción. Muchachos y turislas que más bien se distralan y no atendlan a la voz del pastor. Lo cual me da la dimensión de nuestros auditorios, sin embargo, siempre hay que sembrar. $Y$ el Papa lo estaba haciendo incansablemente" (9 de mayo de 1979).

Asimismo distrutaba participando de las celebraciones masivas. Duranle su primera visita le tocó pasar en Roma la festividad de San Pedro y San Pablo en las cuales particiṕ y se sintió un poco como en una liesta religiosa popular de El Salvador. En la noche del 28 de junio fue a San Pedro, "cuando estaban can. tando las visperas del patrón... También aqul el canto solemne de las visperas, en un ambiente de fiesta, una concurrencia universal, que llenaba el coro de la basílica, me ha traldo tantos recuerdos. Y ahl junto a la tumba de San Pedro, recé el credo de los apóstoles pidiéndole al Señor la lidelidad y la claridad, para creer y predicar esa misma fe del apóstol San Pedro" (28 de junio de 1978). Al día siguienle asistió a la misa solemne de la mañana, la cual encontró "impresionante, mucha genle entra y sale; llena la plaza y las calles adyacentes. Una verdadera fiesta patronal, pero con carácter universal. Asi como en nuestros pueblos las fiestas patronales dan cita a todas las gentes de todos los cantones y pueblos vecinos; esta fiesta de San Pedro, ecuménica, en vez de cantones y pueblos vecinos aqul gente de todos los palses del mundo. Pero el esplritu es el mismo. Una fiesta popular, una fiesta alegre, inspirada por la te y la esperanza. Unas ventas, una compras, un ir y venir de la gente, una alegrla, lo que produce el eslar en contacto con aquellos héroes que ya vencen y reinan en la eternidad, mientras nosotros peregrinamos tratando de imitar sus ejemplos" (29 de junio de 1979).

En abril de 1979 lo encontramos participando en la ceremonia de beatificación de Francisco Coll, pero esta vez como invitado especial. De todos 
modos gozb mucho, "he visto de cerca al Santo Padre, he gozado mucho con aquel coro, con aquella participación del pueblo. No hay duda que la renovación lítúrgica ha cambiado notablemente el triunlalismo de olros tiempos en una verdadera asamblea de oración, de rellexión... El Papa con su sencillez característica, sin silia gestatoria, carninando con todos los concelebrantes es objeto de un entusiasmo cada vez mayor" (29 de abril de 1979). Más tarde, ese mismo dla, asistió al Angelus en la Plaza de San Pedro y la recorrío de noche, paseando, "regresé con la satisfacción de haber vivido un dla tan lleno y feliz con esta Roma inmortal" (29 de abril de 1979). Al dla siguiente participo en actividades culturales y litúrgicas de Indole diversa en honor del P. Coll, "senti la alegría de esta vida de la Iglesia que siempre es fecunda en santidad" (30 de abril de 1979).

En su primera estancia, en el Diario destaca una larga entrevista con el $P$. Pedro Arrupe a quien visitó por primera vez el 16 de junio, recién llegado a la ciudad y después de haber estado en la baślica de San Pedro. Siguiendo el consejo de sus asesores fue a la casa general de los jesuitas a buscar la forma de hacer llegar sus informes a las altas esferas del Vaticano. De esle primer encuentro con el Padre Arrupe afirma que tue "muy amable y generoso, nos ofrece todos los servicios de la Compañía de Jesús" (16 de junio de 1978). El 25 de junio tuvo lugar la conversación más larga. Estas fueron sus impresiones sobre el Padre Arrupe, "es ampliamente comprensivo de que en la Iglesia hay corrienles muy diversas y que hemos de tener conciencia de seguir como nuestra conciencia nos indica y tralar de que el Papa esté bien inlormado de nueslra actuación y de nuestras intenciones... Es un hombre muy santo y se ve que el esplrilu de Dios lo ilumina para tener un espíritu tan abierto y tan comprensivo del momento" (25 de junio de 1978).

En su segunda estancia destaco una visila a la casa general de los claretianos, donde lo invitaron a cenar. Entonces recordó sus años de seminario menor y la primera misa, la cual celebró precisamente en el templo anexo. Los claretianos le pidieron un autógrafo para el libro de visitas en el cual puso las siguientes palabras, "hoy he vuelto a mis orlgenes... Al cenar con ustedes, he recordado el seminario menor que hice con los queridos padres claretianos. $Y$ en este lugar celebré mi primera misa en 1945. Gracias y bendición" ( 3 de mayo de 1979). Este viaje parece haber estado marcado por eslos recuerdos tan prolundos de su juvenlud, pues también visitó la Universidad Gregoriana, "me asomé al aula principal y a todos aquellos claustros que me recuerdan los años de mi juventud estudiantil. Recordé tantas cosas..." (3 de mayo de 1979). Estos recuerdos tan romanos en él revivían "la fe y el entusiasmo sacerdolal" (28 de enero de 1980).

Aprovechando esta segunda estancia en Roma, gracias a un donativo de unas religiosas, se decidió a hacer el báculo que "siempre he deseado, parecido al que usó Pablo VI y sigue usando Juan Pablo Il... representará el Sanlo Cristo en lorma de báculo" (5 de mayo de 1979).

Antes de salir de Roma una de sus últimas visitas era a la basllica de San Pedro, "junlo a la tumba de San Pio $X$ oré intensamente, teniendo en cuenta todos los intercesores que significan para $\mathrm{ml}$, sobre todo los sepulcros de San $\mathrm{Pe}$ dro y de los últimos papas" (9 de mayo de 1979). Con tantos recuerdos y consolaciones personales y pastorales, a Monseñor le costaba dejar Roma, "a pesar 
de regresar a mi patria, siento nostalgia dejar a Roma. Roma es hogar para el que tiene fe y tiene sentido de Iglesia. Roma es la patria de todos los cristianos. Ahl está el Papa que es verdadero padre de todos. Lo he sentido tan cerca; voy tan agradecido con él que el corazón, la le, el esplritu siguen alimentándose de esta roca, donde la unidad de la lglesia se sienle lan palpable* (29 de junio de 1978).

Al regresar a San Salvador después de este primer viaje a Roma lo esperaba "una muchedumbre de gente buena que me acoge con aplausos, con bienvenidas". De llopango se trasladaron a la catedral donde presidió la Eucaristla y saludó al pueblo y relató sus impresiones generales. Hizo un llamado a continuar con esperanza (30 de junio de 1978). Su regreso de Roma en mayo de 1979 fue muy distinto. El vuelo lo dedicó a rezar "a ponerme muy en la presencia de Dios, pidiéndole que me iluminara y que nos ayudara a resolver la grave situación que voy a encontrar en el país." En electo, sólo enconlró violencia y tragedia en las mismas gradas de la caledral... (12 de mayo de 1979).

La situación del pals se siguió deteriorando, aumentó la represión y esa catedral a la que volvía siguió manchándose de sangre con masacres en sus escalinatas; dentro se velaban Irecuentemente los cadáveres de los asesinados. Y esto fue asl incluso el dla de su propio funeral.

\section{Las amenazas de muerte}

La represión y las amenazas contra su propia persona acompañaron a Monseñor durante sus tres años de arzobispado. Desde los comienzos de su ministerio arzobispal fue atacado e insultado innumerables veces en los periódicos capilalinos y en los medios de comunicación en general, pero esas amenazas lueron subiendo de tono.

El 1 de junio de 1979, el gobierno del general Romero tomó represalias en contra de un hermano de Monseñor quien tenía un puesto importante en la compañía telelónica ANTEL. Su hermano fue bajando de categoría, "sin duda, es una revancha del gobierno por ser lamiliar mío y siento que mi familia sulra consecuencias de un deber prolético que tengo que cumplir. He tratado de darle ánimos y de decirle que ante toda situación debemos de estar siempre muy fuerles en la esperanza y estar tirmes también en la lucha por la juslicia de nuestro pueblo" (1 de junio de 1979).

A partir del 21 de julio de 1979, según se puede leer en el Diario, los retenes del ejército y de los cuerpos de seguridad lo trataron mal. Ese dia, lo deluvo el retén que estaba en las alueras de San Miguel de Mercedes, Chalalenango, "quizás creyendo que habla armas." Habla también mucha gente detenida a la entrada del pueblo. Monseñor se detuvo saludándolos a todos y quiso reemprender el viaje hacia el pueblo con ellos, pero el oficial de mando le dijo que él sl podía continuar, pero que la gente no podría entrar al pueblo por orden superior, "comenté yo que era una orden irracional puesto que era gente paclfica, mujeres la mayor parte, que venian a cumplir con un deseo de su fe. Pero la razón no entra con esta gente y lamenlé mucho dejarlos..." (21 de junio de 1979). Al saber que habla gente de otro pueblo vecino que tampoco habían dejado entrar, prometió que él los iría a visitar expresamente.

El 16 de agosto, cuando iba a Chalatenango a celebrar la Eucaristía un retén lo bajó del auto antes de llegar y lo caté "como cualquier sospechoso y se 
nola que hay un atán de lucir su prepotencia frente a la lglesia." Duranle la misa noló mucha vigilancia en el templo, "que Dios los perdone," comenló en el Diario (16 de agosto de 1979). Tres dias más tarde, se encontró con otro retén militar. Esta vez en el cantón Los Sítios, Dulce Nombre de Marla, Chalalenango, a donde iba para celebrar la fiesta del maíz. El retén le hizo el consabido cateo a la entrada del cantón sin "respetar la presencia del arzobispo que va a visitar al pueblo que le loca visilar por razones de su ministerio y sospechan hasla el punto de examinar todas las cosas que se llevan en el carro. ¡Dios los perdone y los iluminel" (19 de agosio de 1979). Al igual que en Chalatenango, la Guardia Nacional vigiló la misa y la homilía, "aunque no habla necesidad de dar esta apariencia militar."

Lo mismo sucedió cuando se dirigla a Arcatao a celebrar la liesta patronal, el 24 de agosto, "nos detuvieron bastante, pedimos paciencia... por primera vez me hacen poner las manos sobre el carro y me registran..." Uno de los oliciales a la entrada del pueblo le explicó "que lenian orden de cuidarme y que me dejara y que en la iglesia iban a estar para vigilar. Yo les dije que no era necesario, que más bien que cuidaran ellos al pueblo y que no hacla mucho honor la presencia militar en la iglesia, dada la situación del pals." Estuvieron al comienzo de la celebración, pero convencidos por una de las religiosas, se reliraron "y fueron a hacer capturas en otras partes que sembraron ya un poco de nerviosidad en el ambiente" (24 de agosto de 1979).

El 4 de enero de 1979, por primera vez, Monseñor hace constar en el Diario que le enviaron "una razón confidencial dicha de viva voz por una persona bien informada de que hay amenazas conlra mi persona, pero con la ayuda de Dios, espero superar y seguir sirviendo con lealtad al evangelio y a nuestro pueblo" (4 de enero de 1979).

El 1 de junio, mientras se tomaba "un calecito" con el párroco de Soyapango a quien habian calumniado en los diarios de la mañana del 31 de mayo, Monseñor le contó "cómo lambién a mi me hablan llegado llamadas telelónicas amenazándome de muerte y una tarjeta con la cruz swástica de la UGB, Unión Guerrera Blanca, ordenándome que debo cambiar de modo de predicar, que debo condenar al comunismo, que debo elogiar a los muertos de los cuerpos de segu. ridad, elc... y que si no sigo esa Ilnea que me van a eliminar. Lo cual comprendo que son como amenazas psicológicas para detener la voz que siente en conciencia que no se puede callar para hacer luz en medio de tantas confusiones e inlereses bastardos" (1 de junio de 1979).

El 7 de septiembre tuvo lugar la visita del ministro de delensa del general Romero para ofrecerle seguridad personal. El 11 fue llamado por el nuncio, quien le comentó la preocupación del presidente sobre su seguridad,"que ve muchos peligros y que me ofrecla seguridad." Pero le repitió en respuesta lo que ya había dicho al ministro de delensa, "que tenlamos conlianza en Dios que nos ampararla" (11 de septiembre de 1979). En la noche de ese mismo dla, la superiora religiosa del hospitalito donde residla, recibió una llamada teletónica en la cual le inlormaron que ya iban a recoger los 10 mil colones que Monseñor habla ofrecido por malar a alguien. Cundió la alarma, pero él logró calmar a las religiosas explicándoles que eran llamadas anónimas para sembrar psicosis.

El 5 de noviembre de 1979 recibió una carta contidencial del nuncio de 
Costa Rica en la cual le comunicaba la preocupación existente en la secretarla de Estado del Vaticano por rumores, que consideraban lidedignos, según los cuales la izquierda lo deseaba matar para crear contlictos al gobierno. Este tipo de rumores ya hablan circulado anteriormente, cuando algunos llegaron a acusar a la izquierda de los asesinatos de los sacerdotes. Incluso después del asesinato de Monseñor algunos afirmaron que habla sido la izquierda. Monseñor reflexionó sobre la información del nuncio y asl to hizo constar en su Diario, "esta eventual amenaza contra mi vida que puede trocarse en realidad tiene por finalidad crear problemas a la nueva junta de gobierno y aumentar la confusión en nuestro pueblo. No ha dejado de preocuparme, dada la seriedad del conducto, ya que muchas de estas noticias las he recibido únicamente como comentarios populares, pero aún asi creo que le daré la imporlancia que he dado siempre, un cuidado prudente, pero sin exageraciones" (5 de noviembre de 1979). Al conocer la amenaza, los miembros de la nueva junta de gobierno le ofrecieron protección personal, pero Monseñor respondió "que quería seguir corriendo los mismos riesgos de mi pueblo y que no sería edíficante una seguridad de esa clase. Aproveché para exhortarles a apresurar que vayan convenciendo al pueblo que se va desilusionando si no ve una actividad más rápida en el gobierno" (5 de noviembre de 1979).

El 24 de lebrero de 1980 denunció en la homilla dominical lá amenaza de muerle que habla recibido de parte de la derecha, "también de parte del pueblo, que rodeaba esta rueda de prensa, se expresaron varios pidiendo a los periodistas el apoyo para nuestra dibcesis, para nuestra radio, para el arzobispo..." (24 de febrero de 1980). Por esta razón decidió no salir del país, suspendiendo el viaje a Guatemala a donde pensaba ir para hacer sus ejercicios espirituales con varios sacerdotes de la vicarla de Chalatenango "y porque también mi presencia aqul es muy conveniente en estas horas de conilicto" (24 de febrero de 1980).

El 10 de marzo, después de haber presidido el funeral del fiscal de la república, quien fue un demócrata cristiano asesinado a sangre frla en su casa por los escuadrones de la muerte, en la basilica del Sagrado Corazón de Jesús se encontró una bomba de unas 60 candelas de dinamita que de haber explotado hubiera destruido el templo y las residencias vecinas. Así, de las amenazas anónimas por telélono o escritas la derecha pasó a concrelar sus amenazas. Cuando Monseñor fue intormado del hallazgo comentó en el Diario "he dado gracias a Dios de que nos ha librado de este nuevo peligro y ha salvado también este viejo templo que tanto quieren los capitalinos..." 


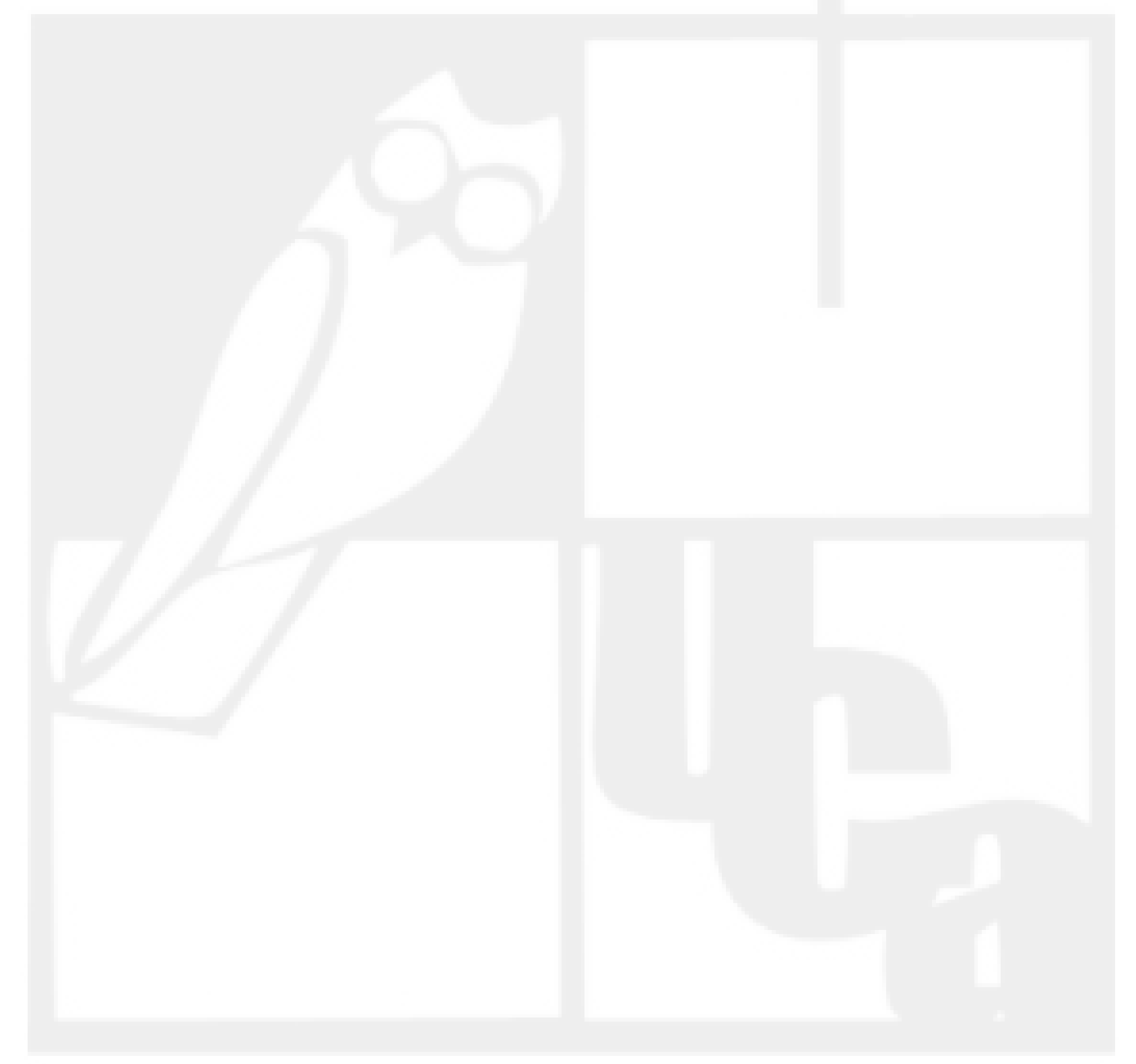

Digitalizado por Biblioteca "P. Florentino Idoate, S.J." Universidad Centroamericana José Simeón Cañas 